\title{
Promoting SME Innovation through Collaboration and Collective-intelligence Network in SMEs: The PMInnova Program
}

\author{
Agostino Villa ${ }^{1}$, Teresa Taurino ${ }^{1}$, \\ Gianni Piero Perrone ${ }^{2}$, Andrea Villa ${ }^{2}$, Enrico Borgo ${ }^{3}$ \\ ${ }^{1}$ Politecnico di Torino, Department of Management and Production Engineering, \\ Corso Duca degli Abruzzi 24, 10129 Torino, Italy \\ ${ }^{2}$ Kiron Organization Secretariat, Via Napoli 40, 15121 Alessandria, Italy \\ ${ }^{3}$ Cassa di Risparmio di Asti S.p.A, piazza Libertà 23, 14100 Asti, Italy \\ \{agostino.villa, teresa.taurino\}@polito.it \\ gp@perrone.it, andrea.villa@,istoreto.it, borgo.enrico@virgilio.it
}

\begin{abstract}
The necessity of SMEs of collaborating together to be competitive again, is mandatory in any European country. Two main perspectives for SMEs to become stronger and stronger: force their collaboration in the project, test and obtain products of high technological level and sophisticated style; inhabit managers to share knowledge, skills and abilities, in order to create a collective intelligence. This is the objective of the PMInnova Program (that means: SME innovation), a strategic agreement between Politecnico di Torino and Gruppo Bancario Cassa di Risparmio di Asti, Biella and Vercelli, dedicated to supporting SMEs both in their innovation projects and in participating in European projects. The work will present some results of the PMInnova Program, for companies in which the use of IoT, AI, and Big Data has been the condition for the creation of the aforementioned collective-intelligence.
\end{abstract}

Keywords: Small and Medium Enterprises, supporting innovation, SME collaboration, PMInnova program, Technology transfer.

\section{Introduction}

The European industrial reality is constituted by $95 \%$ by Small and Medium Enterprises (SMEs) [1]. The main characteristics of SMEs are essentially two: egocentrism, especially in the owners and founders of small enterprises that, over time, have designed high value products; their high consideration of the company and the quality of its products, associated with the fear that the qualifying aspects of their production techniques will be copied by competitors especially of larger dimensions [2].

These two characteristics encourage many managers of SMEs to manage the business in conditions of great confidentiality, imposing on employees the obligation not to disseminate their work, and sometimes neither by patenting their innovations to avoid their future re-use by third parties [3, 4]. 
Such behavior is found in a high percentage of SME managers met under the PMInnova Program, a strategic agreement between Politecnico di Torino and the banking group of the Cassa di Risparmio di Asti, Biella and Vercelli (in Piedmont and part of Lombardy regions, in North-West Italy).

This program is dedicated to promoting innovation and development in SMEs, encouraging collaborations, as will be described in later parts of the work.

Therefore, this work is organized as follows. Section 2 briefly illustrates the objectives of the PMInnova Program, indicating its first results. Section 3 describes how some of the brightest SMEs, in terms of product quality or in terms of technological level work (for reasons of confidentiality names are disguised, however, they will be communicated to each interested reader). Section 4 will present the proposals for technological and / or organizational innovation that are presented to the SME manager. These proposals encourage him to collaborate with other companies in the same sector or in the sectors of machinery manufacturers and ICT services from one side and to promote internal growth with a gradual transfer of knowledge from older operators to younger people on the other side.

\section{Objectives and Activities of the PMInnova Program}

Politecnico di Torino - Department of Management and Production Engineering - and Bank of Asti group have signed a convention to implement a program of consulting, research and training, dedicated to promoting development technology and organization of Micro, Small and Medium Enterprises (SMEs). The agreement is called PMInnova Program - Promoting Innovation and Development in SMEs.

In this context it is expected that the actors of the agreement can support the enterprises in pursuing their innovation goal:

- $\quad$ studying the feasibility of projects and alternative options;

- $\quad$ identifying funding opportunities in European, national or regional context;

- defining the necessary training programs.

More precisely, the activities that are developed in favor of SMEs, especially if customers of Banca di Asti group, are the following:

a) Information on funding programs. The banks in the group, after consulting the Polytechnic, select the SMEs that present innovation plans of particular interest and place them in the PMInnova communication list in order to receive, under an annual subscription, information on open calls in European, national and regional funding programs. It follows that an SME on the PMInnova list may request to take advantage of the activities referred to in the following points.

b) Innovation of SMEs [5]. Once received requests for the implementation of innovation projects sent by SMEs belonging to the aforementioned PMInnova list, the Politecnico di Torino will be able to provide consulting, research and training activities as indicated below: 
b.1. Consulting to meet the needs of innovation or training of SMEs, in terms of feasibility study of the innovation plan, search for funding opportunities both European and national, support for the formulation and development of a specific project, with particular attention to the plan "Industry 4.0" [6, 7];

b.2. Consultancy to support the SME in its participation in a consortium linked to a European project or a national or regional funding program, in order to define, together with the SME itself, the contribution it can provide to the project consortium, the activities to be performed, and the costs to be covered through the financing.

c) Evaluation of the technical-managerial-financial status of an SME belonging to the PMInnova list, which will be jointly developed by Politecnico di Torino and the banks of the group, on the basis of detailed data of the requesting SME, with one or more visits to the company for a deep analysis of its most relevant characteristics and its main strengths and weaknesses [8, 9].

Every communication between the SMEs, Politecnico di Torino and the banks will be managed by the Organizing Secretariat of the PMInnova Program, entrusted by the Bank of Asti to the Non-profit Association "KIRON - Studies on Communication and Organizational Mediation", with operational headquarters in Asti.

About the main fields to which the PMInnova program is dedicated, the following points provide some suggestions:

$>$ problems of industrial security and cyber security;

$>$ requirements of energy saving, reduction of consumption, use of renewable energy sources;

$>$ the need for "lean industrial organizations" to allow real-time control of quality, costs and waste;

$>$ the need for innovative logistics management, to maximize the level of customer service $[10,11]$;

$>$ the growing need to apply efficient automation, information and communication technologies, even in small production and/or service systems, within the "Industry 4.0" program, also with attention to the needs of effective communication and company promotion.

As regards SME support for European projects proposals, the PMInnova program's objective is to support Italian SMEs that could contribute as a partner in the project consortium, to help them to provide input for the proposal and contributions to the project itself.

It is also expected that banks of the group Banca di Asti and Politecnico di Torino will promote, within the PMInnova program, events and/or conferences on specific topics of innovation and development of SMEs, as well as "invitations for new ideas" for graduating students of Politecnico di Torino and other European universities. 


\section{Brief Analysis of Some Smart SMEs}

As can be understood from section 2, the agreement of one of the four collaboration activities between Politecnico and the enterprise requires a preliminary meeting (brief and dedicated to mutual knowledge) between a professor of the Polytechnic and the manager/owner of the SME asking for support to innovate. From this meeting derives very useful knowledge not only of the type of management but also of the PMI and its limits.

In one month and a half, more than 25 enterprises had a meeting in Politecnico.

The first example of smart SMEs met is an enterprise specialized in the design and prototyping of special hydraulic lifting systems for any type of machine or large objects. Its activity ranges from self-propelled cranes to aerial platforms, to special lifting structures. On the basis of information and requirements of the clients, they start a complete process starting from the project of the system to its construction and implementation, by giving an answer to the customer needs. Typical examples are the large molds for mechanical production.

The company, which employs 15 people, has been repeatedly awarded the gold medal at the International Grand Prize for Inventions.

It is evident that in this SME an internal collective intelligence is very developed, thanks to its small size and to a young staff with strong individual motivations. However, it suffers from two critical issues: on the one hand it presents serious difficulties of interaction with other companies, mainly suppliers to which a specific component is requested; on the other hand, while wishing to participate in European projects, it fears the dissemination of its ideas.

The second company plans and builds for over twenty years electronic products for safety within each production company (especially mechanical), using precision measurement sensors and technologies for the application of infrared and ultrasound. It has recently decided to design and produce optoelectronic equipment for safety barriers. This SME, producing for mechanical production companies related to the automotive sector in the Turin area, has suffered much from the recent economicfinancial crisis and has been forced to halve its staff.

The third company deals with the production of special bolts, dedicated almost exclusively to safety systems in the automotive sector. About thirty years ago, the company was founded by the current owner who is still "the technological soul". With each acquisition of a new order for a new product to be printed, the organization of the work begins with the study of the mold based on the design of the product itself (executed in co-design with the large automotive company to which the product is designated), to move on to the production phase of the new mold and the best production cycle of the final product.

The company consists of three departments:

- $\quad$ first molding department with two machines consisting of 6 presses to form a circle plus eight single presses, some threading machines and one washing unit;

- a finishing department that includes lathes and tappers;

- a special department consisting of two multiple presses during installation.

Excluding the latter, the average age of the other machines exceeds 18 years. 


\section{Proposals for Technological-organizational Innovation}

The most interesting PMI, for an analyst who intends to develop a feasibility study for a company innovation project, is the third one described.

In it, the molding and finishing department have machines with simple but efficient automatisms. They do not have any data collection, analysis and transfer tool to the management system.

The simplest and most effective innovation consists, therefore, in the following interventions:

- to equip the pallets of material and products, both semi-finished and finished, of RFID for their easy recognition;

- to arrange RFID readers in correspondence with the loading/unloading systems of each machine and along the paths of the pallets from one machine to another, thus obtaining a network for collecting data and transferring information to the management system, in analogous form to an IOT network [12].

Regarding the design of each new mold, it is necessary to organize a project group that includes, in addition to the current (few) experts, line operators who can provide indications on defects found in production.

It would also be useful, but in a subsequent step, to equip the group with "collective intelligence" on the aforementioned S/W tools that facilitate proposals and modifications of molds by using Augmented Intelligence tools for an a-priori evaluation of the effects of certain forms on the compression process of the material.

The response of an analyst to the innovation request of the second of the three SMEs mentioned is simpler and more complex at the same time.

More complex as the manager of the PMI lives in a situation of progressive and strong contraction of his business. To this, it can only be remedied by a strong decision, linked to an equally robust innovation initiative.

It is also true that the company has recently decided to invest in the design and production of optoelectronic equipment for safety barriers for machine tool operators.

For this system two possible developments could be obtained:

- In the IOT optics, by using the equipment not only as "screens" for security, but also as "sensors" of production flows;

- by creating, with the use of low-frequency lasers, a network of linear sensors in the entire factory through which there could be a continuous monitoring of a large number of "state variables" of the plant.

The first company mentioned in section 3 is, at the same time, the best from the technological point of view, the most structured in terms of collective intelligence but also very "closed" with respect to possible collaborations.

This characteristic is the consequence of its way of working, of its internal organization and of its way of interacting with the clients.

Moreover, its strength lies precisely in its "collective intelligence" which is also the motive of its excellent image towards a client park that includes all the best multinationals, from aeronautics to automotive, from gas to tires. 
In this case, the analyst has only one suggestion: carefully take care of a gradual rejuvenation of the "collective intelligence".

\section{Conclusions}

In this work, we wanted to present a new (and perhaps only) initiative: the agreement between a technical university (the Polytechnic of Turin) and a Banking Group (Cassa di Risparmio of Asti, Biella and Vercelli) to develop an initiative which sees both of them as providers of knowledge, advice, research and training for SMEs.

SMEs have been, for a long time, forgotten by the great national and European programs since the goal was to support big enterprises to allow Europe to compete globally. Now, we realize that over $60 \%$ of employed people work in micro, small and medium-sized enterprises: a workforce that demands attention from governments and economic and cultural institutions.

\section{References}

1. Muller P., Jenna J., Herr D., Koch L., Peycheva V., McKiernan S.: Annual report on European SMEs 2016/2017. Editor Karen Hope. doi: 10.2873/742338) (2017)

2. Bititci U.S., Martinez V., Albores P., Parung J., Creating and managing value in collaborative networks, in International Journal of Physical Distribution \& Logistics Management, vol. 34, no. 3-4, pp. 251-268 (2004)

3. Camarinha-Matos L.M., Afsarmanesh H., Collaborative Networked Organizations - A Research Agenda for Emerging Business Models, Kluwer Academic Publishers, Boston (2004)

4. Camarinha-Matos L.M., Afsarmanesh H., Collaborative networks: a new scientific Discipline, in Journal of Intelligent Manufacturing, vol. 16, no. 4-5, pp. 439-452 (2005)

5. Kuen-Hung T., Collaborative networks and product innovation performance: Toward a contingency perspective, in Research Policy, vol. 38, pp. 765-778. (2009)

6. Huxham, C., Creating Collaborative Advantage, Sage Publications, London. (1996)

7. McLaren T., Head M., Yuan Y., Supply chain collaboration alternatives: understanding the expected cost and benefits, Internet Research: Electronic Networking Applications and Policy, vol. 12, no. 4, pp. 348-364 (2000)

8. Taurino T., Villa A., From SMEs networks towards collaborative management, in Procedia Manufacturing, vol. 13, pp. 1297-1304 (2017)

9. Ollus M., Jansson K., Karvonen I., On the management of collaborative networks, Symp. Cost Oriented Automation, La Habana, Cuba, (2017)

10. Taurino T., Villa A., Developing collaborative manufacturing in small and medium-sized enterprises, 24th International Conference on Production Research - New challenges for production Research. 30 July - 03 August 2017, Poznan, Poland (2017)

11. Taurino T., Villa A., From Industrial Districts to SME Collaboration Frames, in International Journal of Production Research (2017)

12. Wortmann F., Fluchter K.: Internet of Things - Thecnology and Value Added. Bus Inf Syst Eng 57(3):221-224 DOI 10.1007/s12599-015-0383-3 (2015) 